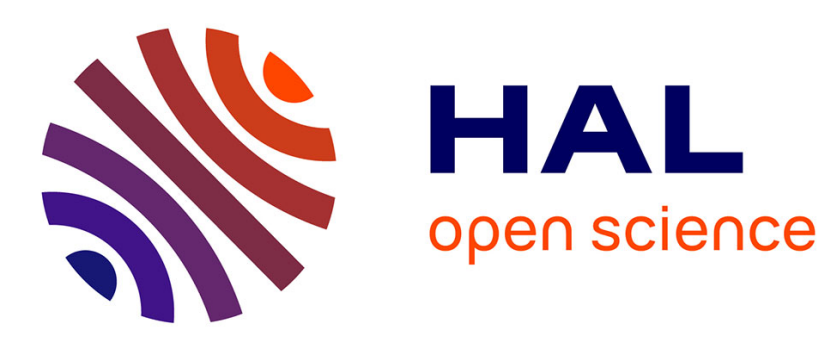

\title{
Découverte d'un trésor du début du XIVe siècle dans une majolique avignonnaise
}

\author{
Lucy Vallauri, Jean-Louis Charlet
}

\section{To cite this version:}

Lucy Vallauri, Jean-Louis Charlet. Découverte d'un trésor du début du XIVe siècle dans une majolique avignonnaise. Archéologie du Midi Médiéval, 1987, 5, pp.183. halshs-01383133

\section{HAL Id: halshs-01383133 \\ https://shs.hal.science/halshs-01383133}

Submitted on 18 Oct 2016

HAL is a multi-disciplinary open access archive for the deposit and dissemination of scientific research documents, whether they are published or not. The documents may come from teaching and research institutions in France or abroad, or from public or private research centers.
L'archive ouverte pluridisciplinaire HAL, est destinée au dépôt et à la diffusion de documents scientifiques de niveau recherche, publiés ou non, émanant des établissements d'enseignement et de recherche français ou étrangers, des laboratoires publics ou privés. 


\section{Découverte d'un trésor du début du XIVe siècle dans une} majolique avignonnaise

In: Archéologie du Midi médiéval. Tome 5, 1987. p. 183.

Citer ce document / Cite this document :

Vallauri Lucy, Charlet Jean-Louis. Découverte d'un trésor du début du XIVe siècle dans une majolique avignonnaise. In: Archéologie du Midi médiéval. Tome 5, 1987. p. 183.

http://www.persee.fr/web/revues/home/prescript/article/amime_0758-7708_1987_num_5_1_1162 


\section{VAUCLUSE}

\author{
Découverte d'un trésor du début du XIVe siècle \\ dans une majolique avignonnaise \\ L. VALLAURI, URA 6 du C.N.R.S. \\ J.-L. CHARLET, Université de Provence
}

En Avignon, en 1986, des travaux d'élargissement des rues Favart et Corderie qui relient la place SaintPierre à la place de l'Horloge ont permis la découverte fortuite d'un lot de 135 monnaies (prises encore dans des lambeaux de tissu grossier) et contenues dans le fond d'une cruche émaillée. L'inventeur de cette découverte a bien voulu nous confier l'étude des monnaies et de la céramique, dont l'inventaire exhaustif a fait l'objet d'une récente publication (1). L'analyse chronologique des monnaies autorise à dater ce petit magot du second semestre 1309 ou de 1310.

$\mathrm{Ce}$ fond de cruche à panse globulaire et fond plat, façonné dans une argile calcaire est émaillé à l'extérieur seulement. Le décor (géométrique?) peint au vert de cuivre et brun-mauve de manganèse s'organise en médaillons circulaires. Un graffiti mal lisible a été peint en brun sous le pied (lettre? signature du potier ou représentation stylisée d'un oiseau?). Le fond repercé après cuisson indique clairement une réutilisation de ce vase à liquide en pot de fleur avant d'avoir servi à cacher le petit trésor (2).

La qualité de la pâte, la technique de revêtement et la morphologie de cette cruche, renvoient aux premières productions de faïence régionale dont le développement est bien attesté en Provence dès la fin du XIII ${ }^{c}$ siècle, et tout au long du XIV ${ }^{c}$ siècle (3). Cette découverte de l'une des plus anciennes majoliques datées en Avignon avec autant de précision, confirme les débuts de la pro-
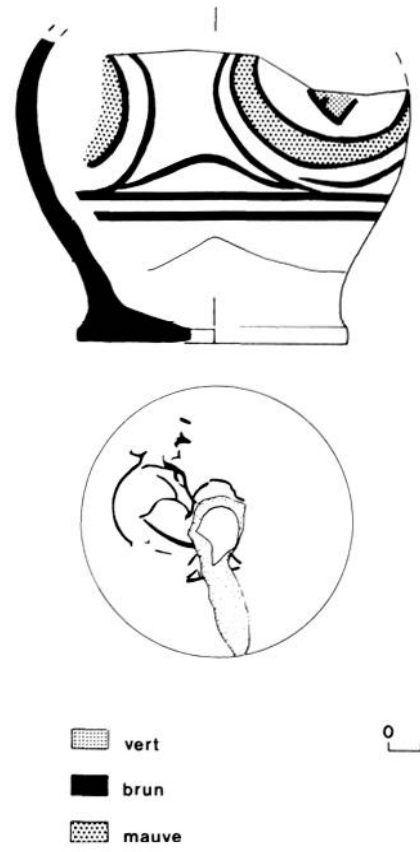

duction régionale dans cette région rhodanienne. L'enfouissement de ces petits magots, témoins de gestes quotidiens, restent d'autre part, pour le céramologue un des critères de datation les plus précieux. Ce trésor de la première décennie du XIV $\mathrm{XV}^{\mathbf{c}}$ s., s'ajoute à la découverte de deux autres lots de monnaies trouvés l'un dans un "pégau " du XIII' siècle dans les Hautes-Alpes, l'autre dans une tirelire en pâte calcaire rhodanienne, cachée dans l'angle d'une maison de l'lle Saint-Geniès à Martigues (Bouches-du-Rhône) à la fin du XIVe siècle (4).

(1) Jean-Louis CHARLET, avec le concours de Christian DUMAS, Un petit trésor du début du XIVc siècle trouvé en Avignon. L. VALLAURI, «étude de la poterie ", Annales du Groupe numismatique du Comtat et de Provence, Avignon, 1986, p. 34-38.

(2) Procédé souvent observé en particulier dans le matériel avignonnais, G. DEMIANS D'ARCHIMBAUD, L. VALLAURI. J. THIRIOT. Céramique d'Avignon. les fouilles de l'hôtel de Brion. Académie de Vaucluse, fascicule hors série, 1980, p. 79, fig. $27 / 3$.

(3) G. DEMIANS D'ARCHIMBAUD, Les fouilles de Rougiers, contribution à l'archéologie de l'habitat rural médiéval en pays méditerranéen. ed. du C.N.R.S., Paris, Valbonne, 1980, pp. 364-378.

L. VALLAURI, M. VICHY, R. BROECKER, M.C. SALVAIRE, "Les productions de majoliques archaïques dans le Bas-Rhône et le Roussillon ", La céramique médiévale en Méditerranée occidentale, X'-XVe siècles, Valbonne, 1978-1980, ed. du C.N.R.S., pp. 413-427.

(4) Aujourd'hui le Moyen Age. Archéologie et vie quotidienne en France méridionale, catalogue de l'exposition, Aix-en-Provence, catalogue de l'exposition, Aix-en-Provence, 1981, p. 82, n 323-326. 